\title{
INFORMASI KEBIJAKAN LARANGAN KANTONG PLASTIK TERHADAP MINAT BELI TAS RAMAH LINGKUNGAN
}

\author{
Pramelani \\ Universitas Bina Sarana Informatika, pramelani@gmail.com
}

\begin{abstract}
ABSTRAK
Limbah sampah plastik di Indonesia sangat meningkat dan dapat membahayakan bagi lingkungan. Maka, pemerintah memberlakukan kebijakan larangan kantong plastik sekali pakai. Ada beberapa daerah yang telah menetapkan kebijakan tersebut. Sedangkan, pemerintah di DKI Jakarta sedang mempersiapkan kebijakan larangan kantong plastik sekali pakai. Selama enam bulan, pemerintah mengadakan sosialisasi terhadap kebijakan tersebut. Dan informasi kebijakan larangan kantong plastik sekali pakai sudah diinformasikan dari tahun kemaren. Dan tas ramah lingkungan juga diinformasikan sebagai penggantinya. Penulis tertarik untuk meneliti mengenai informasi kebijakan yang didapatkan oleh masyarakat tersebut. Sehingga, penelitian ini bertujuan untuk mengetahui hubungan Informasi Kebijakan Larangan Kantong Plastik terhadap Minat Beli Tas Ramah Lingkungan. Responden dipilih yang tinggal di daerah DKI Jakarta dan dengan teknik convenience sampling. Metode penelitian yang digunakan adalah kuantitatif. Sedangkan, analisa data di uji dengan korelasi spearman. Hasil dari korelasi tersebut adalah terdapat hubungan yang kuat.antara informasi kebijakan larangan kantong plastik dengan minat beli tas ramah lingkungan
\end{abstract}

Kata Kunci : Informasi, Kebijakan, Minat Beli

\begin{abstract}
Plastic waste in Indonesia is very increasing and can endanger the environment. So, the government imposed a ban on disposable plastic bags. There are several regions that have established these policies. Meanwhile, the government in DKI Jakarta is preparing a ban on disposable plastic bags. For six months, the government held a socialization of the policy. And information on the policy of prohibiting disposable plastic bags has been informed from yesterday. And eco-friendly bags are also informed as a replacement. The author is interested in researching policy information obtained by the community. Thus, this study aims to determine the relationship of Information Policy to the Ban on Plastic Bags to the Interest in Buying Environmentally Friendly Bags. Respondents were selected who lived in the DKI Jakarta area and by convenience sampling technique. The research method used is quantitative. Whereas, data analysis was tested by spearman correlation. The result of this correlation is that there is a strong relationship between information on the prohibition of plastic bags and the interest in buying eco-friendly bags
\end{abstract}

Keywords: information, policies, buying interest

\section{PENDAHULUAN}

Sampah kantong plastik di Indonesia sangat memprihatinkan bagi lingkungan. Berdasarkan data yang diperoleh dari Kementerian Lingkungan Hidup dan Kehutanan (KLHK) menunjukkan jumlah sampah mencapai hampir 38,5 juta ton per tahun di daerah perkotaan. Atau dapat disimpulkan bahwa pertumbuhan 2-4\% setiap tahun. Data tersebut juga diperlihatkan bahwa 17\% dari 200 ribu ton per total sampah setiap hari berasal dari sampah plastik. Sedangkan 62\% adalah sampah kantong belanja. (Kusuma, 2018). 
Pemerintah sangat khawatir terhadap limbah sampah plastik semakin meningkat. Indonesia pun dinilai sebagai negara kedua di dunia yang membuang sampah plastik ke laut. Melihat demikian, pemerintah berencana untuk mengurangi sampah plastik yang telah terjadi di Indonesia.

Dalam pengurangan sampah plastik, beberapa pemerintah di daerah masingmasing yang sudah mulai atau yang berencana di tahun ini akan mengeluarkan kebijakan larangan kantong plastik sekali pakai. Ada 4 (empat) kota yang sudah mengeluarkan peraturan daerah pengurangan sampah plastik yaitu:

a. Banjarmasin.

Sejak 1 Juni 2016, tertuang pada Peraturan Wali Kota (Perwali) Banjarmasin Nomor 18 tahun 2016 tentang Pengurangan Penggunaan Kantong plastik

b. Balikpapan

Bulan Juni 2018 sudah mulai mengurangi kantong plastik dengan dikeluarkannya Peraturan Wali Kota (Perwali) Banjarmasin Nomor 18 tahun 2016.

c. Bogor

Pemerintahan Bogor mulai resmi 1 Desember 2018 pengurangan penggunaan kantong plastik pusat perbelanjaan modern dimana telah tertuang pada Peraturan Wali Kota (Perwali) nomor 61 tahun 2018

d. Denpasar

Sedangkan pemerintah Denpasar melakukan pelarangan per tanggal 1 Januari 2019 dimana sudah dilakukan kampanye pengurangan kantong plastik sejak tahun 2017.(IreneWibowo25, 2018)

Sedangkan, pada pemerintah daerah Jakarta masih menyiapkan kebijakan tersebut dimana menurut Djafar Muchlisin selaku Wakil Kepala Dinas Lingkungan Hidup DKI Jakarta menargetkan 2 (dua) bulan ke depan peraturan tersebut sudah rampung. Dan kemudian, pergub selama enam bulan bersosialisasi ke warga Jakarta. (Sari, 2019)
Larangan penggunaan kantong plastik sekali pakai sudah diinformasikan dari tahun kemaren di berbagai media dan terjun langsung bersosialisasi ke pasar-pasar pedagang serta pembeli salah satunya di PD Pasar Jaya. Pemerintah mengedukasi masyarakat di ritel-ritel, sekolah-sekolah, pasar-pasar dan lain-lain untuk menghimbau agar tidak menggunakan kantong plastik lagi tetapi beralih ke tas ramah lingkungan. Pemprov DKI menyebutkan dalam kebijakan larangan kantong plastik tersebut akan ada sanksi atau denda bagi yang melanggar yakni sebesar Rp 5 juta sampai dengan Rp 25 juta (Indozone.id, 2018)

Melihat fenomena tersebut, penulis tertarik untuk melakukan riset mengenai informasi kebijakan larangan kantong plastik sekali pakai terhadap minat beli tas ramah lingkungan khususnya masyarakat yang berada di daerah Jakarta. Dengan demikian, rumusan masalah dalam penelitian ini adalah "Apakah terdapat hubungan Informasi Kebijakan Larangan Kantong Plastik terhadap Minat Beli Tas Ramah Lingkungan."

Penulis melakukan riset ini bertujuan untuk mengetahui hubungan Informasi Kebijakan Larangan Kantong Plastik terhadap Minat Beli Tas Ramah Lingkungan.

Sedangkan manfaat yang dapat diambil dari penelitian yakni:

a. Secara teoritis

Hasil penelitian ini dapat dimanfaatkan menjadi bahan referensi bagi mahasiswa, atau para peneliti selanjutnya dimana tertarik melakukan riset lebih dalam mengenai kebijakan larangan kantong plastik sekali pakai.

b. Secara praktis

Riset ini juga bermanfaat sebagai bahan masukan bagi pemerintah, serta para pengusaha di bidang produksi tas ramah lingkungan.

\section{KAJIAN LITERATUR \\ Komunikasi}

Komunikasi memiliki definisi berlalunya informasi, pertukaran ide atau proses 
pembentukan keawaman atau kesatuan pemikiran antara pengirim serta penerima. (Sabrina, Azwar, \& Sofa, 2017)

Definisi tersebut juga dikemukakan oleh Zulkarnain \& Sumarsono dimana komunikasi adalah menyebarkan atau memberitahukan informasi kepada pihak lain agar memiliki maksud yang sama. (Hernandeni, Bafadal, \& Maisyaroh, 2018)

\section{Informasi}

Komunikasi yang dikirimkannya berupa informasi tentang kebijakan larangan Kantong Plastik Sekali Pakai. Informasi adalah data yang diolah atau diinterpretasikan yang ditujukan dalam proses pengambilan keputusan. (Hakim \& Mustaqiem, 2018)

Pendapat Sunarya, dkk berpendapat bahwa informasi merupakan data yang diproses ke dalam suatu bentuk yang mempunyai makna untuk si penerima bagi keputusan saat ini atau keputusan mendatang. (Parlina, Mawarni, \& Safitri, 2018)

\section{Kebijakan}

Definisi kebijakan dari Carl Friedrich adalah arahan suatu tindakan yang dicetus oleh pemerintah dalam lingkungan tertentu yang memberikan hambatan dan peluang yang kemudian diusulkan untuk digunakan dan mengatasi tujuan dan merealisasikan sasaran yang dituju. (S Arum, 2016)

Hal senada yang dikemukakan oleh Islamy bahwa kebijakan publik tersebut adalah serangkaian tindakan yang dilakukan oleh pemerintah dimana memiliki tujuan demi kepentingan masyarakat.(Zuhad, 2018)

Kebijakan di penelitian ini berkenaan dengan Larangan Kantong Plastik Sekali Pakai yang akan diterapkan di daerah DKI Jakarta oleh pemerintah.

\section{Minat Beli}

Minat beli adalah faktor pendorong dalam pengambilan keputusan pembelian terhadap suatu produk. (Firona \& Iskandar, 2018)
Di samping itu, minat beli disebutkan pula oleh Durianto dan Liana sebagai sesuatu yang berhubungan dengan rencana konsumen untuk membeli produk tertentu dan jumlah unit produk yang dibutuhkan pada periode tertentu. (Dianita \& Arifin, 2018)

Berdasarkan pendapat Ferdinand, indikatorindikator pada minat beli yakni:

a. Kesadaran adalah timbulnya perhatian konsumen terhadap suatu usaha pemasaran yang diberikan oleh pemasar.

b. Minat adalah munculnya minat beli konsumen tertarik terhadap objek yang dikenalkan oleh pemasar.

c. Keinginan adalah setelah merasa tertarik, timbul hasrat atau keinginan untuk memiliki objek tersebut.(Dianita \& Arifin, 2018)

Hipotesis dalam penelitian ini adalah "Terdapat hubungan Informasi Kebijakan Larangan Kantong Plastik terhadap Minat Beli Tas Ramah Lingkungan".

\section{METODE PENELITIAN}

Metode penelitian yang digunakan adalah penelitian kuantitatif yang merupakan pendekatan yang bersifat objektif dengan mengumpulkan, menganalisa data kuantitatif serta menggunakan metode pengujian statistik.(Hermawan \& Yusran, 2017)

Populasi dalam penelitian ini yakni masyarakat daerah Jakarta dimana telah mengetahui informasi kebijakan Larangan Kantong Plastik Sekali Pakai. Namun, penulis dalam pengambilan sampel digunakan teknik convenience sampling. Teknik ini adalah penulis dapat menentukan sampel apa saja, namun sesuai dengan populasi sasaran yang sudah ditetapkan.(Eriyanto, 2015)

Sampel yang diambil oleh penulis dalam riset ini berjumlah 52 responden. Jumlah masih dalam range pengambilan sampel yang dijelaskan oleh pendapat Roscoe bahwa penentuan ukuran sampel berjumlah lebih dari 30 dan kurang dari 500. (Pramelani, 2018) 
Dalam mengolah data, penulis dibantu oleh program SPSS (Statistical Package for the Social Sciences) versi 17.0. Sedangkan untuk penganalisaan data digunakan uji korelasi. Korelasi adalah teknik untuk mengetahui seberapa besar hubungan antar variabel.dimana derajad koefisien antara $0,00-0,199$ menunjukkan tingkat korelasi sangat rendah, dan jika nilai korelasi antara $0,60-0,799$ memperlihatkan kuatnya hubungan antar variabel. (Ismail, 2018)

\section{PEMBAHASAN}

Variabel-variabel penelitian dari kuesioner yang disebar ke 52 sampel di berada daerah Jakarta, dapat diketahui distribusi jawaban responden sebagai berikut:

Tabel 1. Distribusi Pendapat Responden Tentang Informasi Kebijakan Larangan Kantong Plastik Sekali Pakai

\begin{tabular}{cccccccccccccc}
\hline \multirow{2}{*}{ Skor } & \multicolumn{1}{c}{1} & \multicolumn{1}{c}{2} & \multicolumn{1}{c}{3} & \multicolumn{1}{c}{5} & \multirow{2}{*}{$\sum \mathrm{F}$} & \multirow{2}{*}{$\mathrm{F} \times \mathrm{S}$} \\
\cline { 2 - 12 } & $\mathrm{F}$ & $\%$ & $\mathrm{~F}$ & $\%$ & $\mathrm{~F}$ & $\%$ & $\mathrm{~F}$ & $\%$ & $\mathrm{~F}$ & $\%$ & & \\
\hline 1 & 0 & 0 & 0 & 0 & 0 & 0 & 0 & 0 & 0 & 0 & 0 & 0 \\
\hline 2 & 0 & 0 & 0 & 0 & 5 & 9.6 & 0 & 0 & 1 & 1,9 & 6 & 12 \\
\hline 3 & 0 & 0 & 0 & 0 & 0 & 0 & 0 & 0 & 0 & 0 & 0 & 0 \\
\hline 4 & 34 & 65.4 & 27 & 51.9 & 32 & 62 & 30 & 57,7 & 31 & 59,6 & 154 & 616 \\
\hline 5 & 18 & 34.6 & 25 & 48.1 & 15 & 29 & 22 & 42,3 & 20 & 38,5 & 100 & 500 \\
\hline \multirow{2}{*}{ Total } & 52 & 100 & 52 & 100 & 52 & 100 & 52 & 100 & 52 & 100 & 260 & 1128 \\
\hline
\end{tabular}

Sumber: Olah Data Penulis (2019)

Dari tabel 1 menunjukkan total dari jawaban responden mengenai Informasi Kebijakan Larangan Kantong Plastik Sekali Pakai sebesar 1128. Sedangkan skor tertinggi yang ideal adalah $5 \times 5 \times 52=1300$. Sehingga persentase skor yang diperoleh dari skor yang dicapai berbanding dengan skor tertinggi adalah $86,77 \%$.

Kriteria interpretasi skor skala likert dapat dihitung dengan rumus (Prisilia, Tombeng, Rengkung, \& Waney, 2018):

Keunggulan Kompetitif $=$ Jumlah Skor Hasil Pengumpulan Data $\times 100 \%$ Jumlah Skor Tertinggil

Dengan hasil perhitungan interpretasi nilai bahwa nilai persentase terendah adalah $20 \%$ dan nilai tertinggi $100 \%$.

Maka, kriteria nilai interval sebagai berikut:
Tabel 2. Kriteria Penilaian Interval

\begin{tabular}{ccl}
\hline No. & Persentase (\%) & \multicolumn{1}{c}{ Kategori } \\
\hline 1 & $84 \%-100 \%$ & Sangat Baik \\
\hline 2 & $68 \%-83.99 \%$ & Baik \\
\hline 3 & $52 \%-67.99 \%$ & Sedang \\
\hline 4 & $36 \%-51.99 \%$ & Kurang Baik \\
\hline 5 & $20 \%-35.99 \%$ & Sangat Kurang Baik
\end{tabular}

Sumber : Olah Data Penulis (2019)

Berdasarkan skor yang dicapai dari jawaban responden terhadap pertanyaan tentang informasi kebijakan larangan kantong plastik sekali pakai yaitu $86,77 \%$, jika dilihat dari kriteria penilaian masuk ke dalam kategori sangat baik yang mengartikan responden sangat setuju terhadap informasi yang diperoleh terhadap kebijakan yang akan diberlakukan oleh pemerintah berkenaan dengan penggunaan kantong plastik sekali pakai.

Tabel 3. Distribusi Pendapat Responden Tentang Minat Beli Tas Ramah Lingkungan

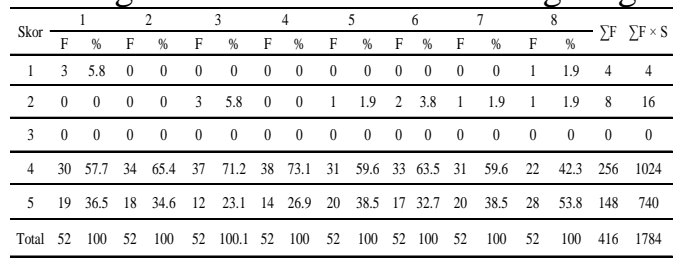

Sumber: Olah Data Penulis (2019)

Tabel 3 menunjukkan bahwa total skor sebesar 1784 dimana skor tertinggi adalah $5 \times$ $8 \times 52=2080$. Jadi persentase skor yang dicapai berbanding dengan persentase skor tertinggi sebesar $85,77 \%$. Dan nilai persentase tersebut masuk ke dalam kategori sangat baik pada tabel kriteria penilaian interval atau dapat diartikan bahwa responden sangatsetuju terhadap minat beli tas ramah lingkungan yang ditawarkan oleh penjual agar dapat mengurangi masalah yang terjadi di daerah Jakarta dalam hal mengatasi masalah kantong plastik sekali pakai. 
Kemudian, penelitian dilakukan uji validitas dan reliabilitas. Validitas adalah untuk mengetahui tingkat ketepatan alat ukur. Korelasi setiap item dikatakan valid apabila bernilai positif dan diuji signifikan atau tidak. (Azuar, Irfan, Manurung, \& Satriawan, 2016)

Taraf signifikansi yang digunakan adalah $5 \%$ $(0,05)$ yang kemudian disesuaikan $\mathrm{r}$ tabel berdasarkan jumlah responden ( $\mathrm{N}=50$ orang) dengan rumus N-2. Dan ditemukan hasil $\mathrm{r}$ tabel $=0,279$. Jadi dikatakan valid apabila > 0,279 .

Tabel 4. Validitas Variabel Informasi Kebijakan Larangan Kantong Plastik Sekali

\begin{tabular}{|c|c|c|c|}
\hline Item & $\begin{array}{l}\text { Nilai r } \\
\text { Hitung }\end{array}$ & $\begin{array}{l}\text { Nilai } r \\
\text { Tabel }\end{array}$ & Keterangan \\
\hline butir_1 & 0,603 & 0,279 & Valid \\
\hline butir_2 & 0,515 & 0,279 & Valid \\
\hline butir_3 & 0,736 & 0,279 & Valid \\
\hline butir_4 & 0,649 & 0,279 & Valid \\
\hline butir_5 & 0,651 & 0,279 & Valid \\
\hline
\end{tabular}

Sumber: Olah Data Penulis (2019)

Tabel 5. Validitas Variabel Minat Beli

\begin{tabular}{llll}
\multicolumn{4}{c}{ Tas Ramah Lingkungan } \\
\hline \multirow{3}{*}{ Item } & Nilai $r$ & Nilai $r$ & \\
& Hitung & Tabel & Keterangan
\end{tabular}

\begin{tabular}{cccl}
\hline butir_1 & 0,551 & 0,279 & Valid \\
\hline butir_2 & 0,668 & 0,279 & Valid \\
\hline butir_3 & 0,498 & 0,279 & Valid \\
\hline butir_4 & 0,746 & 0,279 & Valid \\
\hline butir_5 & 0.723 & 0,279 & Valid \\
\hline butir_6 & 0,839 & 0,279 & Valid \\
\hline butir_7 & 0,693 & 0,279 & Valid \\
\hline butir_8 & 0,568 & 0,279 & Valid
\end{tabular}

Sumber: Olah Data Penulis (2019)
Dari tabel 4 dan tabel 5 terlihat semua butir pertanyaan baik dari variabel Informasi Kebijakan Larangan Kantong Plastik Sekali Pakai dan variabel minat beli tas ramah lingkungan adalah valid. Sehingga butir-butir pertanyaan tersebut selanjutnya digunakan untuk uji reliabilitas.

Reliabilitas adalah untuk mengetahui tingkat kepercayaan dengan menggunakan nilai koefisien Cronbach's Alpha $>0,06$ yang berarti nilai instrument memiliki reliabilitas baik. (Azuar et al., 2016)

Tabel 6. Reliabilitas Variabel Informasi Kebijakan Larangan Kantong Plastik Sekali Pakai dan Variabel Minat Beli Tas Ramah Lingkungan

Sumber: Olah Data Penulis (2019)

\begin{tabular}{cccc}
\hline Variabel & $\begin{array}{c}\text { Cronbach's } \\
\text { Coefficient } \\
\text { Alpha }\end{array}$ & $\begin{array}{c}\text { Nilai } \\
\text { Kritis }\end{array}$ & Keterangan \\
\hline $\begin{array}{c}\text { Informasi } \\
\text { Kebijakan }\end{array}$ & 0,617 & 0,60 & Reliabel \\
\hline $\begin{array}{c}\text { Minat beli } \\
\text { Tas }\end{array}$ & 0,784 & 0,60 & Reliabel \\
\hline
\end{tabular}

Data-data yang sudah dikumpulkan kemudian dilakukan pengujian normalitas. Dan hasilnya adalah data-data tersebut tidak berdistribusi normal.

Oleh karena itu, teknik yang paling tepat untuk data tersebut adalah statistik nonparametrik yang merupakan teknik statistika yang parameter populasi dan asumsi distribusinya bebas. Sehingga dalam penganalisa data dapat digunakan korelasi spearman. (Habiby, 2017)

Tabel 7. Uji Korelasi Variabel Informasi Kebijakan Larangan Kantong Plastik Sekali Pakai terhadap Variabel Minat Beli Tas Ramah Lingkungan

\begin{tabular}{|l|c|c|}
\hline & $\begin{array}{c}\text { Total_Min } \\
\text { at_Tas }\end{array}$ & $\begin{array}{c}\text { Total_infor } \\
\text { masi_Kebija } \\
\text { kan }\end{array}$ \\
\hline
\end{tabular}




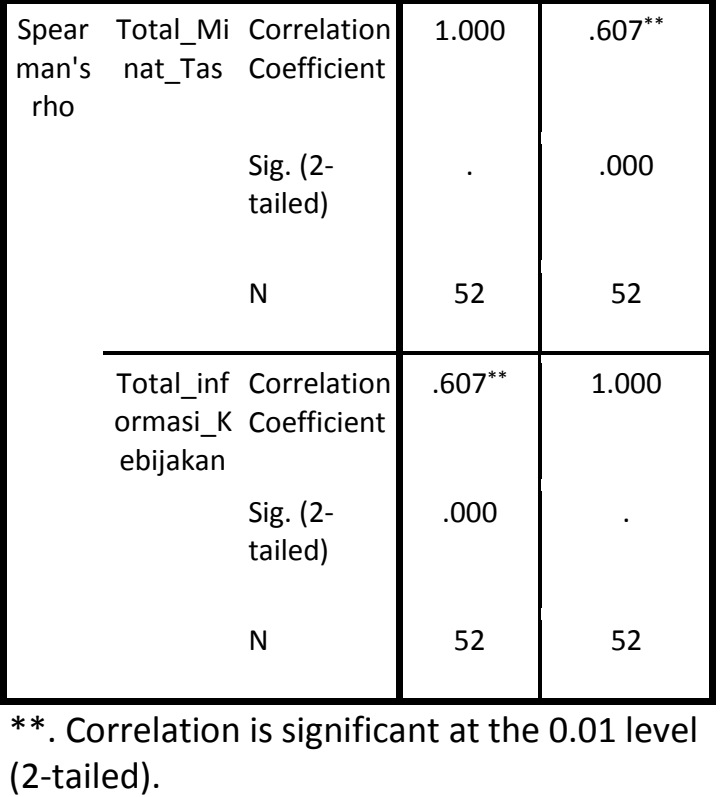

Sumber: Olah Data SPSS Penulis (2019)

Dari tabel 7 terlihat nilai korelasi spearman yang didapat dari program SPSS versi 17.0 yakni sebesar 0,607. Dengan besaran nilai tersebut berdasarkan ukuran nilai korelasi menunjukkan bahwa informasi kebijakan larangan kantong plastik sekali pakai terhadap minat beli tas ramah lingkungan mempunyai hubungan yang kuat.

\section{PENUTUP}

Dengan adanya penelitian mengenai informasi kebijakan kantong plastik sekali pakai terhadap minat beli tas ramah lingkungan didapatkan jawaban bahwa responden sangat setuju terhadap informasi yang diperoleh sangat jelas mengenai kebijakan yang dilakukan oleh pemerintah dalam hal mengatasi masalah kantong plastik sekali pakai denda atau sanksi yang diberikan bagi yang melanggar. Responden pun sangat setuju diberlakukannya kebijakan tersebut dan mendukung pemerintah dalam kegiatan sosialisasi kebijakan pelarangan kantong plastik sekai pakai. Di samping itu, responden berminat membeli tas ramah lingkungan sebagai pengganti dari kantong plastik sekali pakai.

Dalam penganalisaan data disimpulkan juga bahwa antara informasi kebijakan kantong plastik sekali pakai terhadap minat beli tas ramah lingkungan memiliki hubungan yang kuat. Dengan demikian, responden sangat membutuhkan tas ramah lingkungan pengganti dari kantong plastik sekali pakai jika tidak digunakan lagi. Hubungan tersebut terlihat dari uji korelasi yang dihasilkan. Komponen-komponen yang didalamnya terdapat adanya kesadaran, minat dan keinginan untuk membeli tas ramah lingkungan akibat dari informasi kebijakan dari pemerintah tentang larangan penggunaan kantong plastik sekali pakai dimana memiliki dampak yang besar bagi lingkungan alam.

Saran-saran yang dapat diberikan yakni:

a. Bagi peneliti: Dapat menjadi referensi dan dapat dikembangkan variabelvariabel penelitian yang dianggap dapat mempengaruhi kebijakan pemerintah tersebut.

b. Bagi pengusaha: Dapat mengembangkan usaha dalam barang pengganti kantong plastik sekali pakai.

c. Bagi pemerintah: Dapat menjadi masukan terhadap kebijakan kantong plastik sekali pakai.

\section{REFERENSI}

Azuar, J., Irfan, Manurung, S., \& Satriawan, B. (2016). Mengolah Data Penelitian Bisnis Dengan SPSS. (R. Franita, Ed.) (Pertama). Medan: Lembaga Penelitian dan Penulisan Ilmiah Aqli.

Dianita, D. I., \& Arifin, Z. (2018). Pengaruh Brand Ekstensi dan Brand Image Terhadap Minat Beli Pengaruh Brand Ekstensi Iphone Di Kota Malang (Survei pada pengunjung Outlet OPPO Smartphone di Mall Plaza Malang ). Jurnal Administrasi Bisnis (JAB), 64(1), 119-125. Retrieved from http://administrasibisnis.studentjournal. ub.ac.id/index.php/jab/article/view/273 $3 / 3127$

Eriyanto. (2015). Analisis Isi: Pengantar Metodologi Untuk Penelitian Ilmu Komunikasi dan Ilmu-Ilmu Sosial Lainnya. Jakarta: Prenada Media Group.

Firona, W., \& Iskandar, D. A. (2018). 
Pengaruh Direct Selling Dan Media Sosial Melalui Facebook Terhadap Minat Beli Konsumen Pada Rokok Sin Herbal. JRMB: Jurnal Riset Manajemen Dan Bisnis., 3, 213-222. Retrieved from http://jrmb.ejournalfeuniat.net/index.php/JRMB/article/vie $\mathrm{w} / 138$

Habiby, W. N. (2017). Statistika Pendidikan. Surakarta: Muhammadiyah University Press.

Hakim, L., \& Mustaqiem. (2018). Sistem Informasi Penilaian Kinerja Guru Pada SMA NEGERI 2 Sampit Berbasis Desktop. Jurnal Sistem Informasi, 5, 1-6. Retrieved from http://jurnal.unda.ac.id/index.php/Jpdf/ article/view/54/50

Hermawan, A., \& Yusran, H. L. (2017). Penelitian Bisnis Pendekatan Kuantitatif (Pertama). Depok: Kencana Prenada Media Group.

Hernandeni, D. F., Bafadal, I., \& Maisyaroh. (2018). Intensitas Komunikasi Kepala Madrasah, Guru, dan Tenaga Kependidikan Dalam Meningkatkan Mutu Pendidikan. Jurnal Administrasi Dan Manajemen Pendidikan (JAMP), 1, 150-159. Retrieved from http://journal2.um.ac.id/index.php/jam p/article/view/3394/2136

Indozone.id. (2018). Pemprov DKI Akan Siapkan Pergub Larangan Pemakaian Kantong Plastik. Indozone.Id. Retrieved from https://www.indozone.id/news/pempro v-dki-akan-siapkan-pergub-laranganpemakaian-kantong-plastik

IreneWibowo25. (2018). 4 Kota Di Indonesia Ini Mulai Melarang Penggunaan Kantong Plastik. Antaranews.Com. Retrieved from https://www.antaranews.com/berita/77 3652/kota-bogor-resmi-larangkantong-plastik

Ismail, H. F. (2018). Statistika Untuk Penelitian Pendidikan dan Ilmu-Ilmu Sosial (Pertama). Jakarta: Prenadamedia Group.

Kusuma, H. (2018). Kemenkeu Beberkan Alasan Kantong Plastik Perlu Kena Cukai. Detik.Com. Retrieved from https://finance.detik.com/beritaekonomi-bisnis/d-4349504/kemenkeubeberkan-alasan-kantong-plastik-perlukena-cukai

Parlina, A., Mawarni, G., \& Safitri, D. (2018). Media Penunjang Informasi Dan Promosi Berbentuk Katalog Produk Pada PT Ideal Formica Purnatata. CICES JOURNAL, 4(1), 1528. Retrieved from http://ejournal.raharja.ac.id/index.php/c ices/article/view/424/300

Pramelani. (2018). Terpaan Informasi Hoax McDonald di Whatsapp Terhadap Kepercayaan Konsumen. Jurnal Komunikasi, 9(2), 48-53. https://doi.org/https://doi.org/10.31294 /jkom.v9i2.4392.g2706

Prisilia, A., Tombeng, S., Rengkung, L. R., \& Waney, N. F. L. (2018). Keunggulan Kompetitif Produk Tepung Kelapa Pada PT Putra Karangetang Minahasa Selatan. Agri-Sosioekonomi Unsrat, 14 No.1, 81-94. Retrieved from https://ejournal.unsrat.ac.id/index.php/j isep/article/view/18966/18526

S Arum, R. (2016). Implementasi Kebijakan Revitalisasi Pasar Tradisional Di Pasar Bandeng Kota Tangerang. Universitas Sultan Ageng Tirtayasa.

Sabrina, N., Azwar, \& Sofa, N. (2017). Pengaruh Kredibilitas Brand Ambassador Selebriti Pada Iklan Wardah Versi Dewi Sandra ( Studi Kasus Mahasiswi UIN Jakarta Fakultas Ekonomi Dan Bisnis ). Epigram, 14(2), 143-152. Retrieved from http://jurnal.pnj.ac.id/index.php/epigra $\mathrm{m} /$ article/view/1092/658

Sari, N. (2019). Dua Bulan Lagi, DKI Punya Pergub Larangan Kantong Plastik. Kompas.Com. Retrieved from https://megapolitan.kompas.com/read/2 019/01/14/19121611/dua-bulan-lagidki-punya-pergub-larangan-kantongplastik

Zuhad, S. F. (2018). Implementasi Kebijakan Jaminan Sosial Ketenagakerjaan Pada Sektor Publik (Studi tentang Aspek Penahapan Kepesertaan BPJS Ketenagakerjaan di Universitas Brawijaya Malang). JPAP, 
4 No. 1, 980-991. Retrieved from http://jurnal.untag-

sby.ac.id/index.php/jpap/article/view/1 $282 / 1083$

\section{BIODATA PENULIS}

Pramelani, lulusan Magister Manajemen (MM) Program Pasca Sarjana Magister Ilmu Manajemen Universitas Bina Sarana Informatika Bandung tahun 2015 dan selalu aktif dengan kegiatan seminar, pengajaran, penulisan buku, kegiatan keorganisasian serta olahraga. 
